\title{
The global pediatric nephrology workforce: a survey of the International Pediatric Nephrology Association
}

\author{
Dorey Glenn ${ }^{1 *}$, Sophie Ocegueda', Meaghan Nazareth', Yi Zhong ${ }^{1}$, Adam Weinstein ${ }^{2}$, William Primack', \\ Pierre Cochat ${ }^{3}$ and Maria Ferris ${ }^{1}$
}

\begin{abstract}
Background: The global pediatric nephrology workforce is poorly characterized. The objectives of our study were to assess pediatric nephrologists' perceptions of the adequacy of the pediatric nephrology workforce, and understand regional challenges to fellow recruitment and job acquisition. Perceptions regarding optimal length of training and research requirements were also queried.

Methods: A 17-question web-based survey comprised of 14 close-ended and 3 open-ended questions was e-mailed to members of the International Pediatric Nephrology Association. Quantitative and qualitative analyses were performed.

Results: We received 341 responses from members of the International Pediatric Nephrology Association from 71 countries. There was a high degree of overall perceived workforce inadequacy with $67 \%$ of all respondents reporting some degree of shortage. Perceived workforce shortage ranged from $20 \%$ in Australia/New Zealand to $100 \%$ in Africa. Respondents from Africa (25\%) and North America (22.4\%) reported the greatest difficulty recruiting fellows. Respondents from Australia/New Zealand (53.3 \%) and Latin America (31.3\%) reported the greatest perceived difficulty finding jobs as pediatric nephrologists after training. Low trainee interest, low salary, lack of government or institutional support, and few available jobs in pediatric nephrology were the most frequently reported obstacles to fellow recruitment and job availability.

Conclusions: Globally, there is a high level of perceived inadequacy in the pediatric nephrology workforce. Regional variability exists in perceived workforce adequacy, ease of recruitment, and job acquisition. Interventions to improve recruitment targeted to specific regional barriers are suggested.
\end{abstract}

Keywords: Pediatric, Nephrology, Workforce, Training, Global health, Survey

\section{Background}

Workforce and training data are important for resource allocation and strategic planning. There is a paucity of published literature describing the adequacy of the pediatric nephrology (PN) workforce on a global scale [1-4].

Kidney disease is increasingly recognized as an important contributor to the global burden of disease [5-9]. In 2012 chronic kidney disease was ranked $18^{\text {th }}$ in a report on global burden of death [5]. The demand for pediatric nephrologists (PNs) is likely to further expand as the pattern of

\footnotetext{
* Correspondence: dglennmd@gmail.com

'UNC Kidney Center, University of North Carolina at Chapel Hill, 7024

Burnett-Womack, Chapel Hill, NC 27599-7155, USA

Full list of author information is available at the end of the article
}

non-communicable disease in developing countries continues to change and economic development in those regions is able to support a greater range of health care interventions $[10,11]$. The availability of maintenance dialysis, for example, has increased substantially from 1990 to 2010 [6]. The role of pediatric nephrologists, however, extends far beyond the care of patients with acute and chronic kidney disease. PNs support intensive care units, treat complications from non-renal diseases, and fill important educational and administrative roles $[1,12,13]$.

Concern regarding the long term PN workforce within the United States is based on a high number of potential retirees in the field and difficulty recruiting trainees [1]. For example, in 2015 only 37 of 58 available fellowship 
positions were filled [14]. However, to our knowledge, perceived adequacy of the PN workforce have not been systematically described in a context external to the United States.

Some attention has been directed towards the global nephrology workforce shortage by adult nephrologists $[9,15-17]$. Efforts to develop training curricula and expand training opportunities to physicians from resource-limited settings have been made on the part of the International Society of Nephrology and the International Pediatric Nephrology Association (IPNA) for example [15, 16]. The objectives of our study are to describe the perceived adequacy of the PN workforce and understand regional challenges to fellow recruitment and job acquisition.

\section{Methods}

\section{Survey development}

We sought to develop and administer a survey instrument assessing the global PN workforce. Prior to survey development, a MEDLINE search to identify prior evaluations of the global PN workforce was performed, and none were identified. We developed an English language, web-based survey assessing 3 domains: trainee recruitment, job availability, and workforce adequacy. Survey questions were developed with the input of research team members. A draft survey instrument was pre-tested by 5 pediatric nephrologists to assess content validity, interpretability, and length. The draft instrument was updated based on pretesting feedback. The final survey instrument was comprised of 14 close-ended and 3 open-ended questions. Question response types included dichotomous, multiple choice, Likert scale, and free text responses. The survey was developed and deployed via the Qualtrics platform at the University of North Carolina at Chapel Hill (see Additional files 1, 2 and 3) [18]. This study was deemed exempt by the Human Research Ethics Committee of the University of North Carolina Chapel Hill.

\section{Survey administration}

Survey invitations were sent through e-mail to non-North American IPNA members with a valid e-mail address in the online IPNA directory in the fall of 2015. One reminder e-mail was sent 2 weeks later. Survey invitations were sent to North American IPNA members in December of 2015. Implied consent was obtained prior to survey participation. Survey participants received no individual remuneration; however, a donation to IPNA was made on their behalf.

\section{Statistical analysis}

Quantitative data was analyzed using STATA version 13 (College Station, TX) and Microsoft Excel 2013 (Redmond, WA). Survey respondent data were reported as counts and proportions for categorical variables, and medians and interquartile ranges for continuous variables. T-tests were performed comparing ratios of workforce shortage, difficulty recruiting fellows, and difficulty finding a PN job for each region compared to all other regions. T-tests were performed with the allowance for unequal variances. Qualitative analyses were performed using ATLAS.ti version 7 (Berlin, Germany). Thematic analysis was independently performed by two research team members ( $\mathrm{SO}$ and $\mathrm{MN}$ ) to code open-ended questions into 11 themes. Discrepancies between coders were rectified by a third party (DG). Investigator triangulation was used to ensure that the identified themes reflected the range and depth of responses. All survey responses were collected and analyzed anonymously.

\section{Results}

Survey respondents

We received 341 responses from 2304 valid e-mail invitations, yielding an overall response rate of $15 \%$. Responses were received from 71 countries. Regional response rates ranged from $11.2 \%$ in Asia to $31.3 \%$ in Australia and New Zealand.

Tables 1 and 2 display region, practice type, involvement in trainee education, and percent time allocated to clinical practice and research for the survey respondents. Of the 341 respondents, $167(48 \%)$ were affiliated with an academic or university based practice and 206 (60 \%) reported

\begin{tabular}{|c|c|c|}
\hline & Survey respondents & $\begin{array}{l}\text { Survey } \\
\text { non-responders }\end{array}$ \\
\hline \multicolumn{3}{|l|}{ Region } \\
\hline North America & $107(31.4)$ & $566(28.8)$ \\
\hline Latin America & $40(11.7)$ & $225(11.5)$ \\
\hline Europe & $75(22.0)$ & $450(22.9)$ \\
\hline Asia & $61(17.9)$ & $480(24.5)$ \\
\hline Africa & $17(5.0)$ & $66(3.4)$ \\
\hline Australia/New Zealand & $15(4.4)$ & $33(1.7)$ \\
\hline Middle East & $26(7.6)$ & $143(7.3)$ \\
\hline Total & 341 & 1963 \\
\hline \multicolumn{3}{|l|}{ Practice Type } \\
\hline Academia or University Based & $167(49.0)$ & \\
\hline Government Affiliated & $81(23.8)$ & \\
\hline Multiple Practice Types & $65(19.1)$ & \\
\hline Private Practice & $17(5.0)$ & \\
\hline Other & $9(2.6)$ & \\
\hline Military Affiliated & $2(0.6)$ & \\
\hline \multicolumn{3}{|l|}{ Involved in Trainee Education } \\
\hline Yes & $206(60.4)$ & \\
\hline No & 135 (39.6) & \\
\hline
\end{tabular}

${ }^{\mathrm{a}}$ Values presented as $\mathrm{n}(\%)$ 
Table 2 Percent time allocated to clinical pediatric nephrology, research, and other activities by region ${ }^{a}$

\begin{tabular}{|c|c|c|c|c|}
\hline & $n$ & $\begin{array}{l}\text { Clinical Pediatric } \\
\text { Nephrology }\end{array}$ & Research & Other \\
\hline \multicolumn{5}{|l|}{ Region } \\
\hline $\begin{array}{r}\text { North } \\
\text { America }\end{array}$ & 107 & $50.0(50.0-75.0)$ & $25.0(0-25.0)$ & $20.0(0-25.0)$ \\
\hline Latin America & 39 & $66.7(50.0-75.0)$ & $20.0(0-28.6)$ & $14.3(0-25.0)$ \\
\hline Europe & 75 & $75.0(50.0-75.0)$ & $25.0(0-25.0)$ & $20.0(0-25.0)$ \\
\hline Asia & 59 & $50.0(40.0-75.0)$ & $20.0(0-25.0)$ & $25.0(0-25.0)$ \\
\hline Africa & 17 & $50.0(50.0-75.0)$ & $25.0(25.0-37.5)$ & $0(0-25.0)$ \\
\hline $\begin{array}{l}\text { Australia/ } \\
\text { New Zealand }\end{array}$ & 15 & $75.0(50.0-100.0)$ & $0(0-25.0)$ & $0(0-25.0)$ \\
\hline Middle East & 26 & $75.0(50.0-75.0)$ & $25.0(16.7-25.0)$ & $0(0-25.0)$ \\
\hline Total & $338^{b}$ & $66.7(50.0-75.0)$ & $25.0(0-25.0)$ & $14.3(0-25.0)$ \\
\hline
\end{tabular}

aalues presented as median and interquartile range (IQR)

${ }^{\mathrm{b}}$ Three respondents who did not report their time breakdown (1 from Latin

America and 2 from Asia) were excluded from the analysis

involvement in trainee education. The median time percentage allocated to clinical nephrology and research was 66.7 \% (IQR 50.0-75.0) and 25.0 \% (IQR 0-25.0), respectively. Figures 1, 2, and 3 represent the perceived adequacy of the PN workforce, difficulty recruiting trainees, and difficulty finding a PN job after training by region. Figures 4 and 5 display results of qualitative analysis of 456 openended responses querying challenges to $\mathrm{PN}$ trainee recruitment and job acquisition.

\section{North America}

A total of 107 responses (response rate of $15.9 \%$ ) were received from North American PNs (100 from the United States, 7 from Canada). Mexico was included in the Latin
American region. Seventy nine percent of North American respondents reported a mild to severe shortage in the PN workforce (Fig. 1). Of those expressing some degree of shortage, $52 \%$ reported a moderate to severe shortage. North American respondents reported the greatest difficulty recruiting trainees with $76 \%$ reporting this activity to be somewhat to very difficult (Fig. 2). Lack of interest (47\%), low salary (41\%), and hard work/poor work-life balance (35\%) were the most frequently reported challenges to trainee recruitment. See Fig. 4 . Sixty three percent of North American respondents reported it to be somewhat easy to very easy to find a PN job after training, but $48 \%$ noted that geographic distribution of jobs was a challenge to job acquisition (Figs. 3 and 5).

\section{Africa}

Seventeen responses (response rate $20.7 \%$ ) were received from nine African countries. All respondents reported some degree of workforce shortage and $71 \%$ reported a severe shortage. Of the 8 respondents involved in physician training, there was variation in perceived ease regarding trainee recruitment. Lack of institutional or government support and resources was the most frequently sighted reason for difficulty recruiting trainees in respondents from Africa (60\%). The majority (64 \%) also reported it to be somewhat to very easy to find a job after training. Barriers to job acquisition after training included lack of resources (46\%) and lack of PN positions (39\%).

\section{Australia/New Zealand}

Fifteen responses (response rate $31.3 \%$ ) were received from Australia and New Zealand. In contrast to North America, $53 \%$ of respondents reported a mild to severe

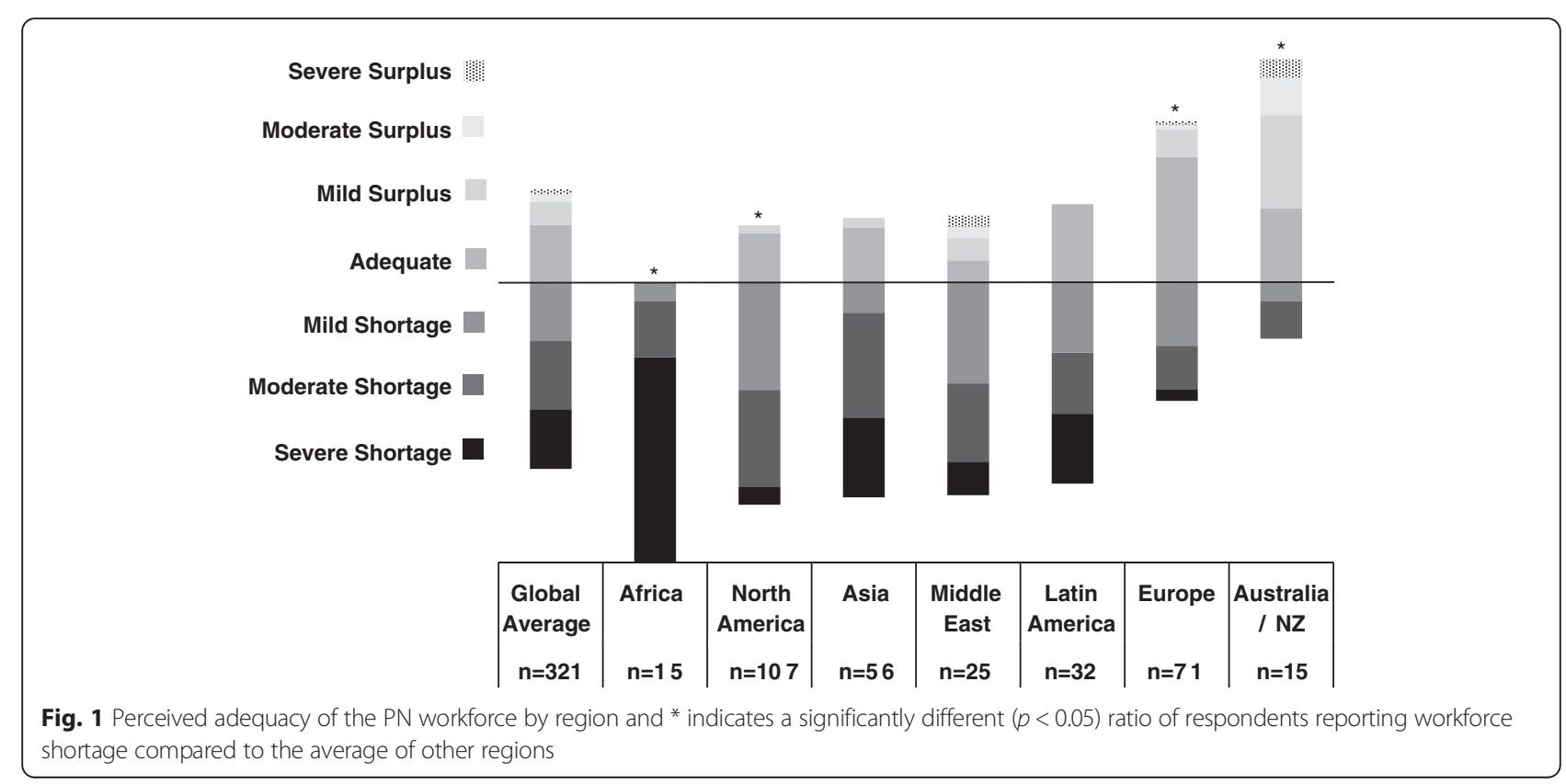




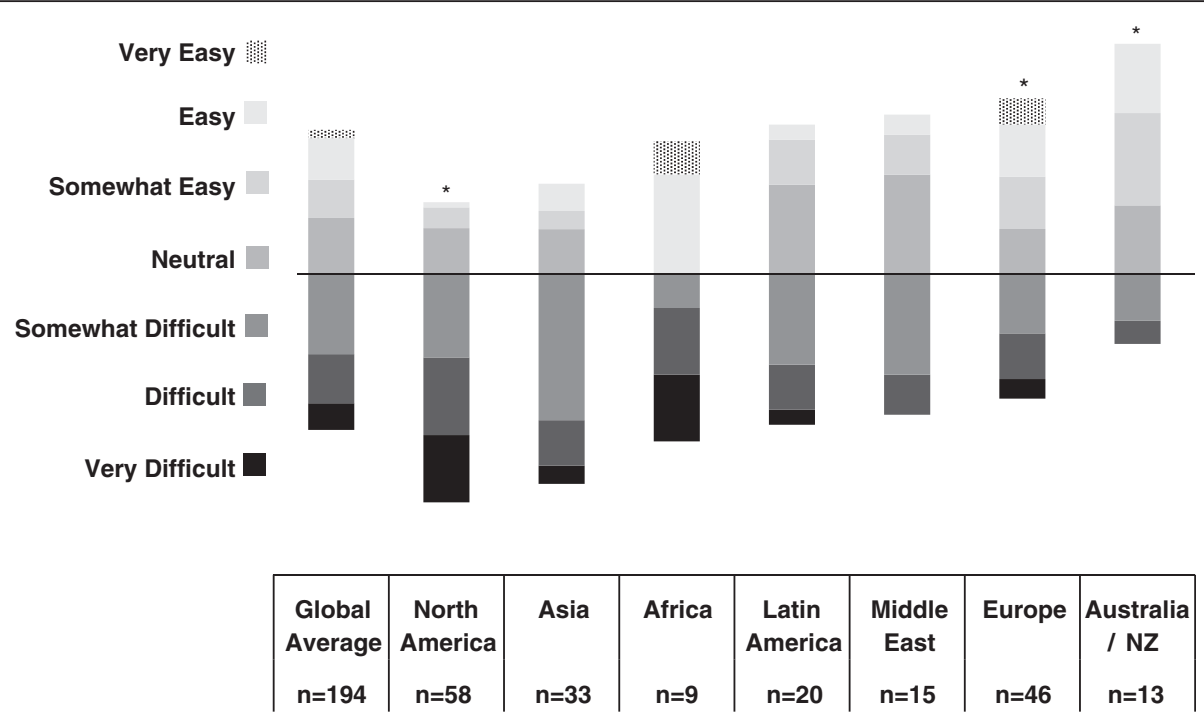

Fig. 2 Perceived difficulty recruiting trainees by region and * indicates a significantly different $(p<0.05)$ ratio of respondents reporting recruitment difficulty compared to the average of other regions

surplus of PNs, and $27 \%$ thought the workforce was adequate. Relative to all other regions, respondents from Australia and New Zealand reported the greatest ease recruiting fellows, $54 \%$ reporting recruitment to be somewhat to very easy. A lack of training positions $(40 \%)$ and low job availability (30\%) were cited as challenges to fellow recruitment. Consistent with the reported relative surplus of PNs, $93 \%$ of respondents reported it to be somewhat to very difficult to find a job after training with $90 \%$ citing a lack of available PN positions as the major obstacle to job acquisition.

\section{Europe}

Seventy five responses (response rate $14.4 \%$ ) were received from 26 European countries. Responses from Russia were included as part of the European region. Fifty eight percent of respondents from Europe felt the PN workforce was adequate or in surplus, which is substantially higher than other regions (with the exception of Australia/NZ). Forty two percent reported a mild to severe shortage. Of the $67 \%$ of European respondents involved in physician training, $41 \%$ reported difficulty, $43 \%$ reported ease, and $15 \%$ were neutral regarding their ability to recruit trainees. More respondents

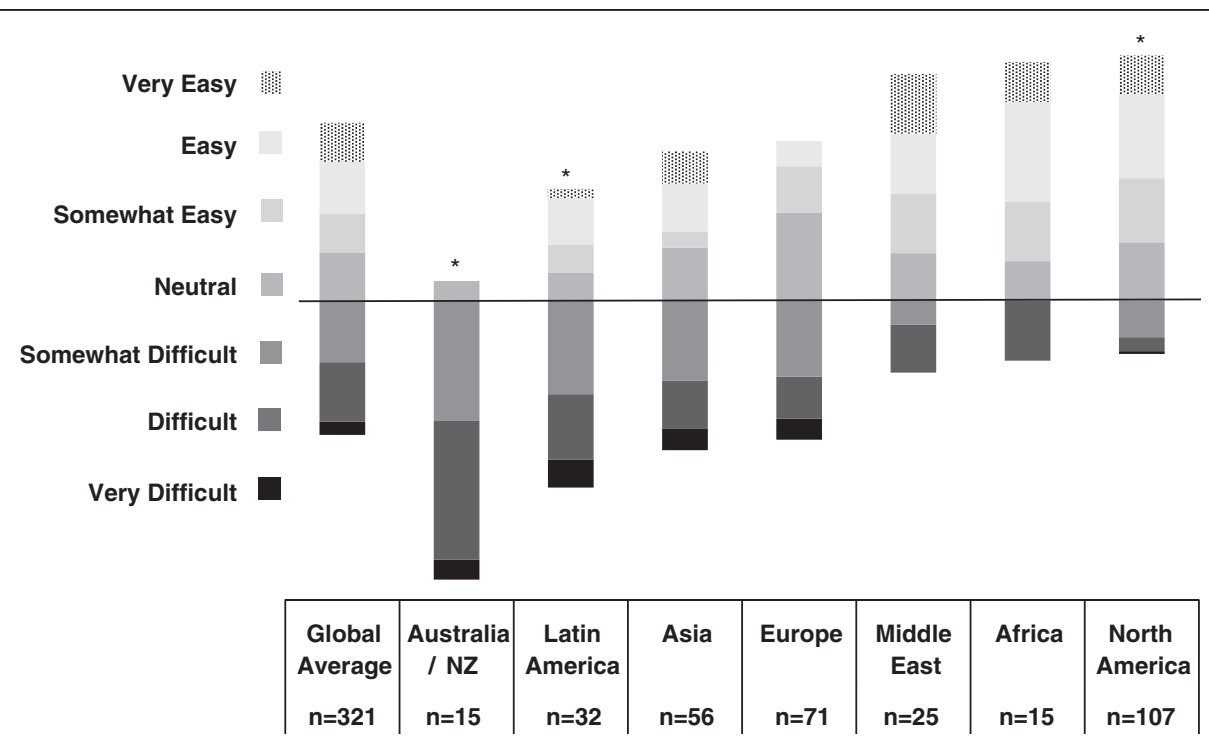

Fig. 3 Perceived difficulty finding a PN job after training by region and * indicates a significantly different $(p<0.05)$ ratio of respondents reporting a perceived difficulty with job acquisition after training compared to the average of other regions 


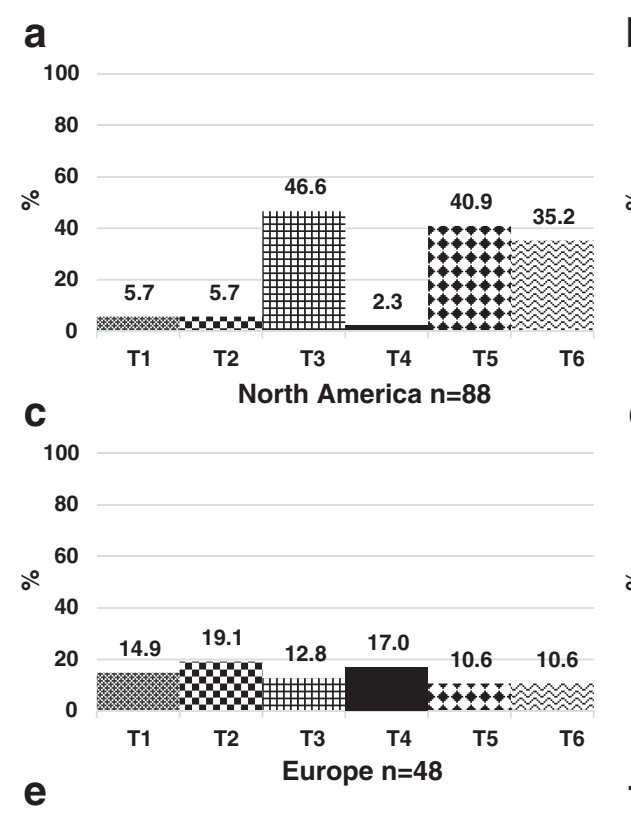

b

100

80

60

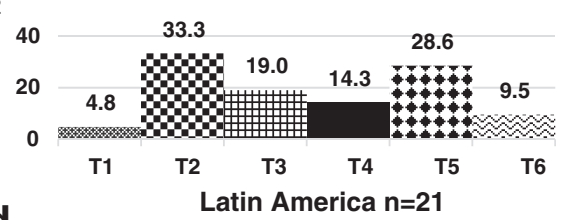

d
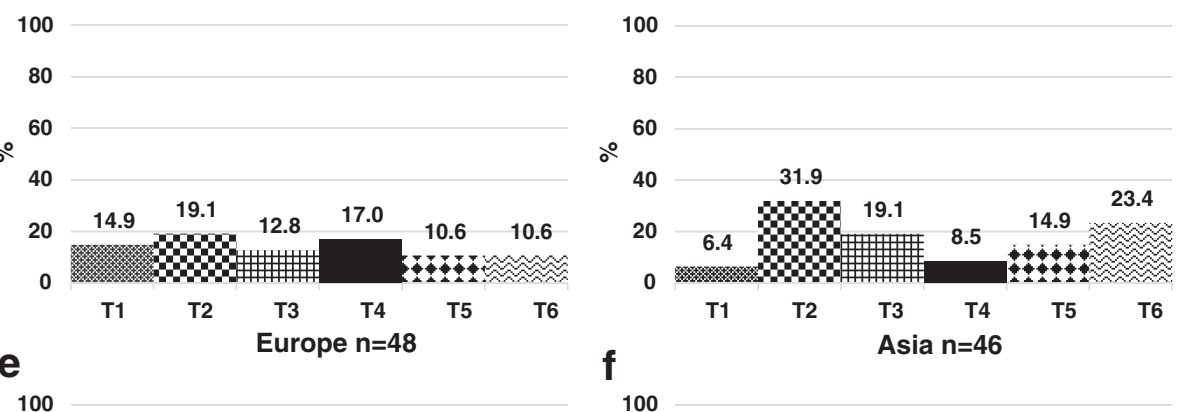

100

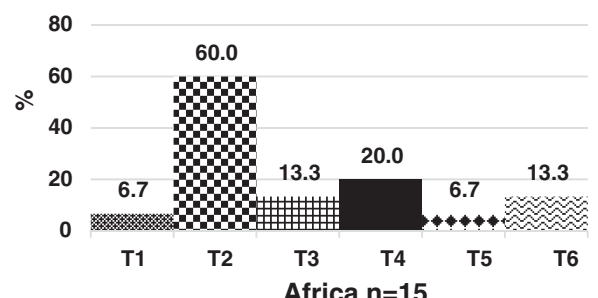

g

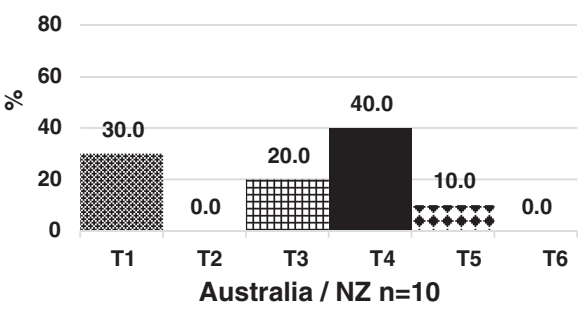

100

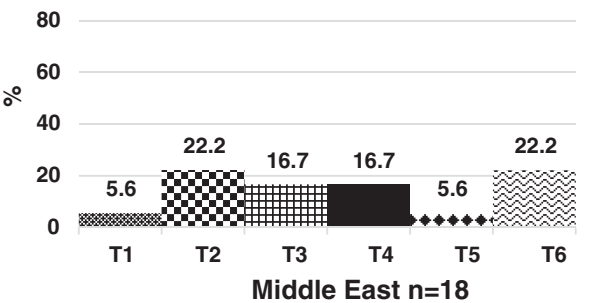

T1 Low Job Availability

X T2 Lack of Institutional or Government Resources / Support

T3 Lack of Trainee Interest

T4 Lack of Training Positions

75 Low Salary

$\approx$ T6 Hard Work / Poor Work-Life Balance

Fig. 4 Results of qualitative analysis of responses to challenges to PN trainee recruitment in North America (a), Latin America (b), Europe (c), Asia (d), Africa (e), Australia and New Zealand (f), and the Middle East (g)

reported difficulty (46\%) than ease (25\%) with job acquisition following training, and $30 \%$ were neutral on this issue. A perceived lack of jobs (71 \%), lack of resources $(20 \%)$, and the geographic location of jobs $(20 \%)$ were the most frequently reported challenges to job acquisition.

Of the 19 respondents from Eastern Europe, 63 \% reported a perceived workforce shortage. This was significantly different $(p=0.038)$ from respondents in Western Europe $(34.6 \%, n=52)$. There were no significant differences in the percent of respondents from these two subregions reporting difficulty recruiting trainees $(p=0.978)$ or difficulty finding a PN job after training $(p=0.127)$.

\section{Latin America}

Forty responses (response rate $15.1 \%$ ) were received from 13 countries in Latin America. For the purposes of our study, we included Jamaica and Mexico as part of Latin America. Twenty eight percent of respondents from Latin America felt the PN workforce was adequate in their country, while $72 \%$ reported a mild to severe shortage. Of the $63 \%$ of respondents involved in physician training, $50 \%$ reported difficulty, $20 \%$ reported ease, and $30 \%$ were neutral regarding their ability to recruit trainees. Lack of institutional or government support and resources (33\%) and low salary (29\%) were the most frequently reported challenges to trainee 
a

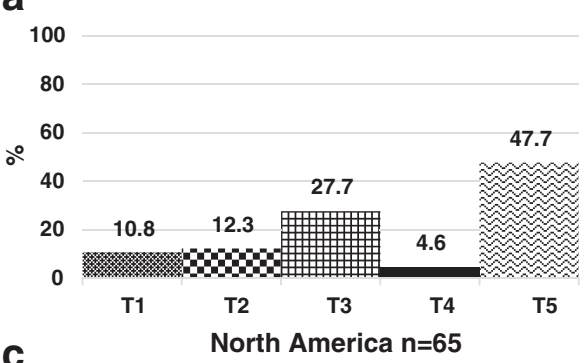

C
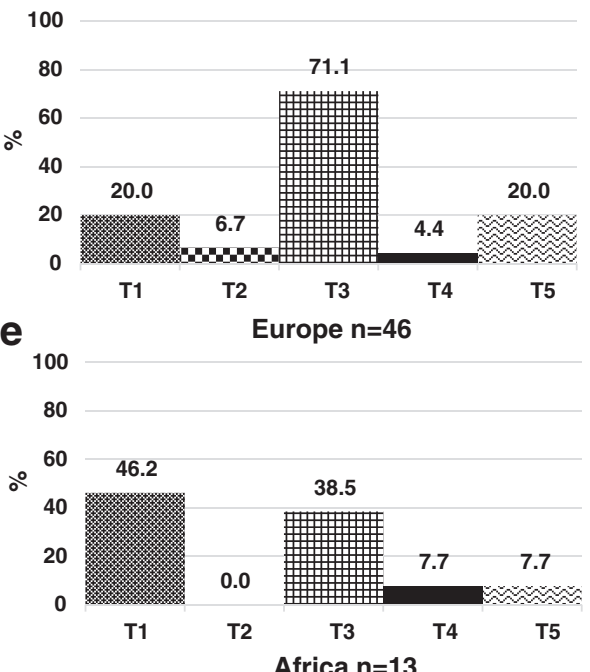

g

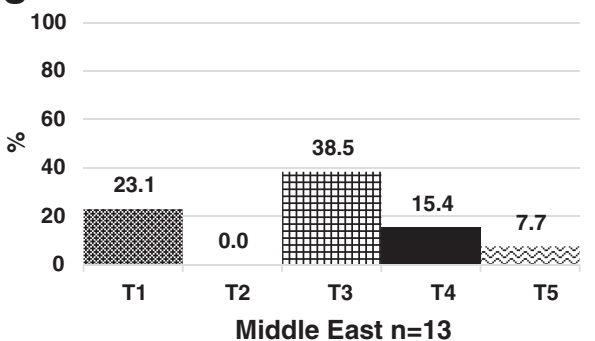

b

100

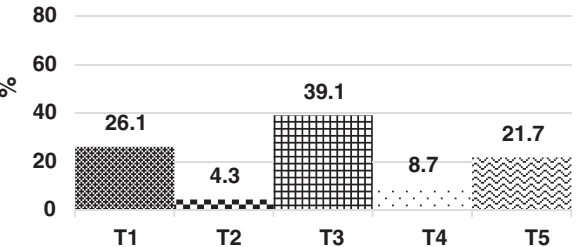

d
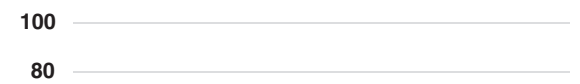

$\circ 60$
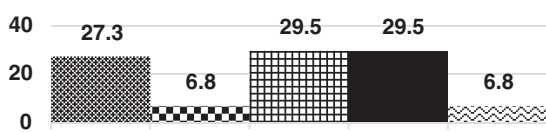

Asia $\mathrm{n}=43$
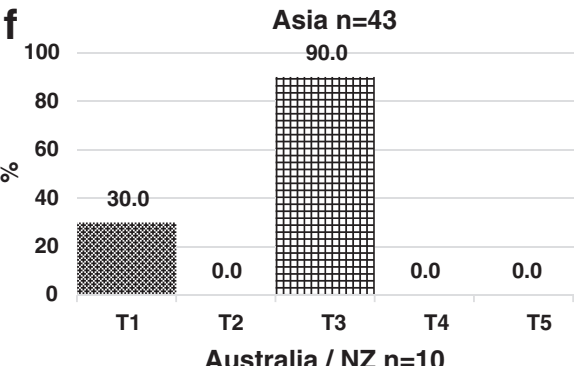

T1 Lack of Resources

$\boldsymbol{X}$ T2 Low Salary

曹 T3 Lack of Pediatric Nephrology Jobs

T4 Unrecognized subspecialty or Adult Nephrologist / General Pediatrician Redundancy

$\approx$ T5 Geographic Location of Job Opportunities

Fig. 5 Results of qualitative analysis of responses to challenges to job acquisition after PN training in North America (a), Latin America (b), Europe (c), Asia (d), Africa (e), Australia and New Zealand (f), and the Middle East $(\mathbf{g})$

recruitment. Two thirds of respondents perceived job acquisition following training to be somewhat to very difficult. The perceived difficulty obtaining a PN job after training in Latin America was significantly higher than the average of other regions. Lack of available PN positions (39\%), lack of resources (26\%), and geographic location of jobs (22\%) were the most frequently reported challenges to job acquisition.

\section{Asia}

Sixty one responses (response rate $11.2 \%$ ) from 12 Asian countries were received. Countries in the Middle East were excluded from the Asian region and analyzed separately. Seventy seven percent of respondents from Asia reported a mild to severe shortage in the PN workforce. Of the $57 \%$ of Asian respondents involved in physician training, $70 \%$ reported difficulty, $15 \%$ reported ease, and $15 \%$ were neutral regarding their ability to recruit trainees. Lack of institutional or government support and resources $(32 \%)$ and hard work/poor work-life balance (23\%) were the most frequently reported challenges to trainee recruitment. Fifty percent of respondents perceived job acquisition following training to be somewhat to very difficult, and $32 \%$ reported it to be somewhat to very easy. Lack of available PN positions (30 \%), lack of resources $(27 \%)$, and poor subspecialty recognition/adult nephrologist redundancy $(30 \%)$ were the most frequently reported challenges to job acquisition after training. 


\section{Middle East}

Twenty six responses from 8 countries were received (response rate $15.3 \%$ ). Turkey was included in the Middle East region rather than Europe or Asia. Seventy six percent of respondents from the Middle East reported a mild to severe shortage in the PN workforce. Of the 58 \% respondents from the Middle East involved in physician training, $47 \%$ reported difficulty, $20 \%$ reported ease, and $33 \%$ were neutral regarding their ability to recruit trainees. Lack of institutional or government support and resources (22\%) and hard work/poor work-life balance (22\%) were the most frequently reported challenges to trainee recruitment. Sixty percent of respondents from the Middle East reported it to be somewhat easy to very easy to find a PN job after training. Lack of available PN positions (39 \%) and lack of resources $(23 \%)$ were the most frequently reported challenges to job acquisition after training.

\section{Training duration and research requirements}

Three years of PN training was perceived as optimal by the majority of respondents in North America, Europe, Asia, Australia/New Zealand, and the Middle East (Fig. 6). The majority of respondents from Latin America and Africa reported that 2 years of PN training is optimal. The percentage of respondents reporting mandatory research requirements in their country varied from $27 \%$ in Europe to $96 \%$ in North America (Fig. 7). In all regions, apart from North America, the percentage of respondents reporting that research or scholarship should be a mandatory part of $\mathrm{PN}$ training was greater than the percentage reporting a current research requirement.

\section{Discussion}

To our knowledge, this survey represents the first global assessment of the PN workforce. PNs in most regions of the world perceive that the $\mathrm{PN}$ workforce is inadequate, with the exception of Australia/NZ and certain areas of Europe, where the workforce is felt to be adequate or even in surplus. Fifty three percent of respondents from Australia and New Zealand reported a mild to severe surplus of PNs, with an additional $27 \%$ reporting the workforce as adequate. Among all regions, respondents from Australia/NZ also reported the greatest difficulty with job acquisition and greatest ease with fellow recruitment. These data suggest an oversupply and/or highly interested pool of potential PN trainees relative to training slots, and a potentially oversaturated or mal-distributed PN job market.

Similarly, though to a lesser extent than Australia/NZ, the majority (58 \%) of European respondents reported workforce adequacy or surplus. Regional variability regarding workforce adequacy has been noted in the adult nephrology community in Europe [15]. Sharif et al. speculated that this variability might be explained by differences in healthcare delivery models, matching of workforce supply to service demands, and the use of physician extenders [15]. We were unable to verify the applicability of these factors to the PN workforce from our data. Factors affecting the supply of adult nephrologists may not translate to the PN workforce due to, for example, contrasting distributions in the public-private sectors and differing training requirements. Our findings from Europe and Australia/NZ stand in sharp contrast, however, to North America, Latin America, Asia, the Middle East, and Africa.

Neither the high degree of perceived workforce inadequacy in North America, nor the challenges to trainee recruitment identified by North American respondents, are surprising $[1,12,19]$. Lack of interest, hard work/ poor work-life balance, and poor salary were obstacles to fellow recruitment reported by more than a third of North American respondents. These themes echo the results of a 2008 survey of U.S pediatric nephrology fellows that reflected lack of interest, financial constraints, and perceived PN workload as factors dissuading potential trainees from PN [20]. Similar themes have been identified as obstacles in the adult nephrology workforce $[15,17]$. In our data, these themes were more frequently reported in North America than in any other region, suggesting that interventions in North America need to be directed toward addressing these obstacles.

Contrasting perceptions between respondents from North America and Europe are particularly noteworthy. Seventy nine percent of North American respondents reported a perceived workforce inadequacy, compared to $42 \%$ of European respondents. Similarly, difficulty recruiting trainees was reported by $76 \%$ of North American respondents, compared to $41 \%$ of European respondents. While our data cannot be used to substantiate objective differences in the PN workforce between these two regions, we hypothesize that perceived differences might be related to variation in the use of physician extenders, the referral patterns of primary care providers, and the relative ease of recruiting and utilizing trainees. Additional research is needed to replicate and further explore these findings.

\section{Suggested interventions to improve the pediatric nephrology workforce Length of training and mandatory research requirements}

Length of training and mandatory research requirements are two factors that might be modified to increase the appeal of PN to potential trainees. The Latin American and African regions were the only regions, however, to prefer 2 years of training over 3 . The data also suggest a greater interest in increasing, rather than decreasing, research/scholarship requirements in all regions other than North America. 


\section{a}

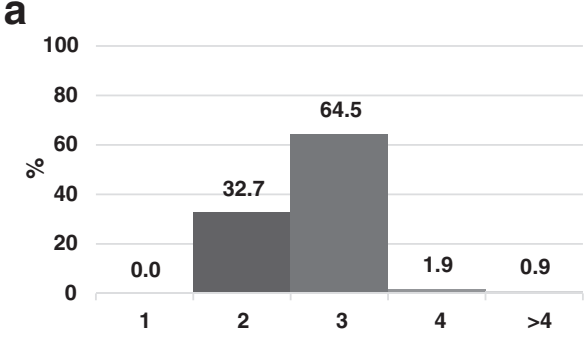

C

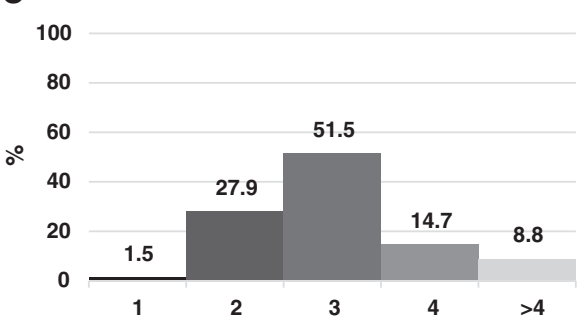

e

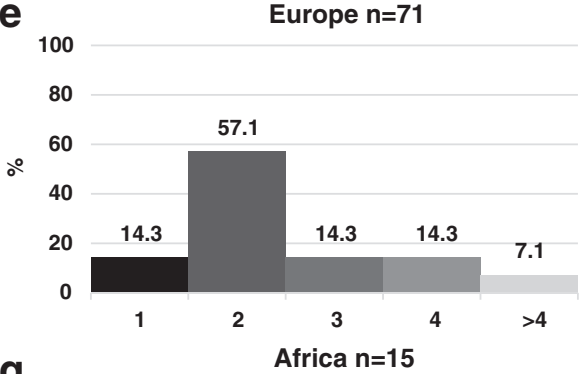

g

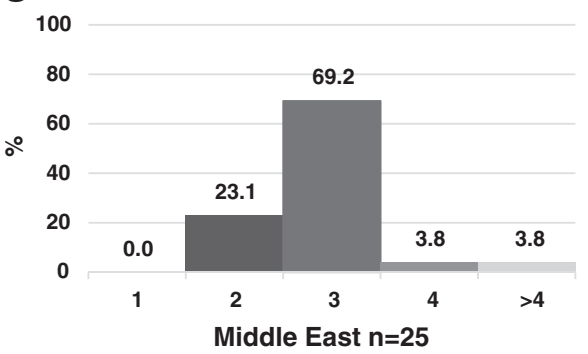

b

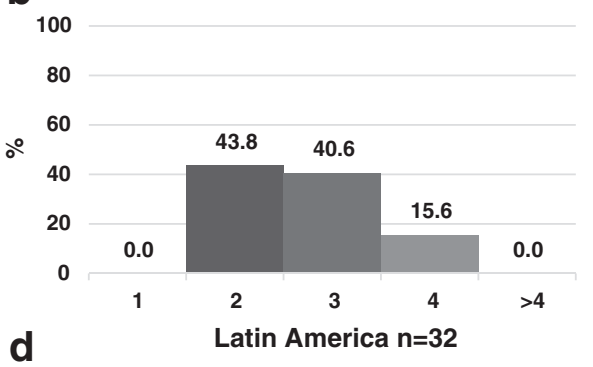

100

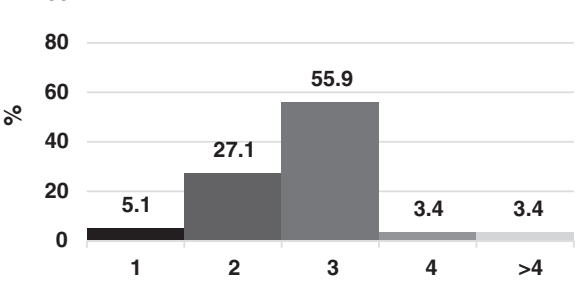

f

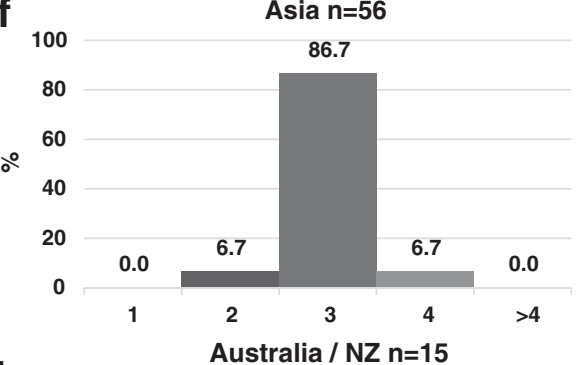

h

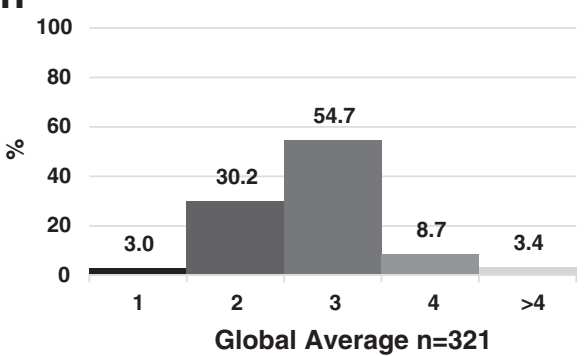

Fig. 6 Optimal years of pediatric nephrology training in North America (a), Latin America (b), Europe (c), Asia (d), Africa (e), Australia and New Zealand (f), Middle East $(\mathbf{g})$, and the global average $(\mathbf{h})$

In our data, $75 \%$ of North American respondents felt that research or scholarly activity should be mandatory; a notable finding given that research is currently a required component of PN fellowship training in the United States. Some North American respondents commented that mandatory research requirements might be a barrier to fellow recruitment, and that a 2 year clinical track might have broader appeal to potential trainees. Nonetheless, the majority (65\%) of North American respondents thought the ideal training duration was 3 years, not two. Decisions to shorten training must be weighed against the importance of broad clinical exposure and the need to train clinician-scholars to advance the field. These data highlight the importance of tailoring training requirements to regional and countrylevel needs and expectations, without sacrificing clinical expertise [10].

\section{Increasing Job opportunities}

Many respondents from Africa (46\%), Asia (27\%), Latin America (26\%), Australia/NZ (30\%), and the Middle East $(23 \%)$ reported that lack of resources was an obstacle to job acquisition. Lack of resources might signify inadequate, aging, or absent infrastructure, insufficient financial support on the part of institutions or governments, or inadequate number of allotted training slots or PN positions. For example, $30 \%$ of Asian respondents reported that redundancy with adult nephrologists or 


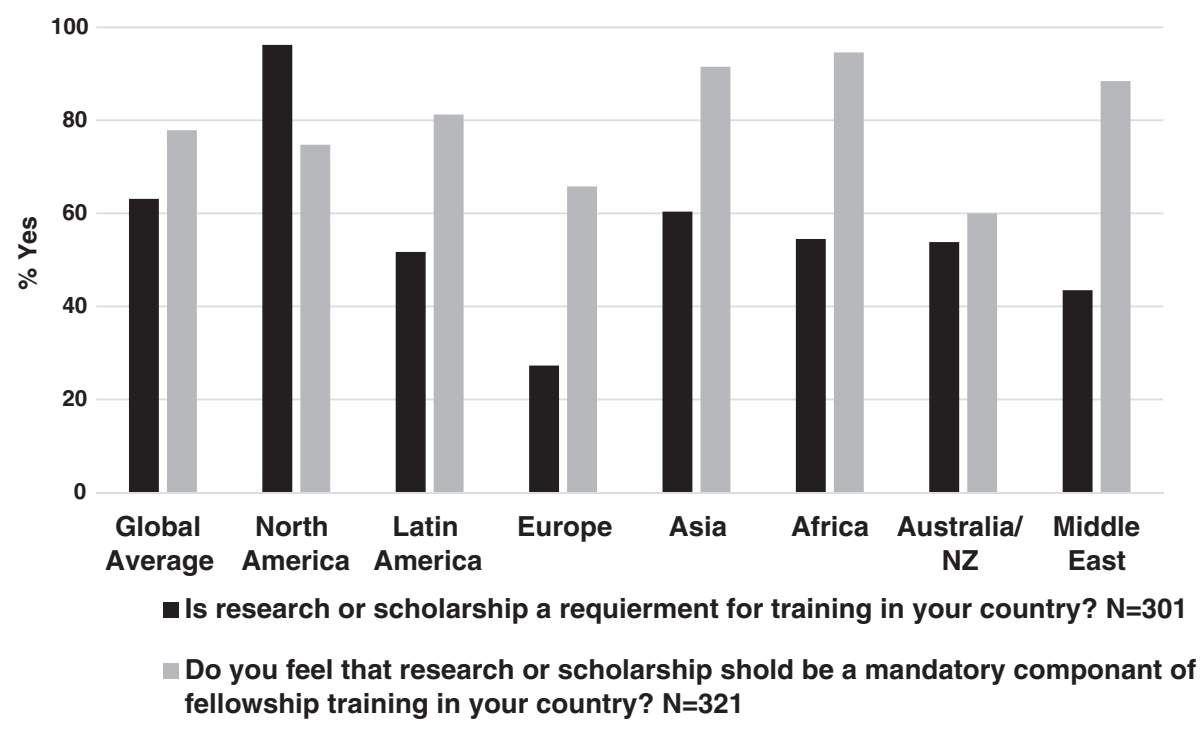

Fig. 7 Actual and desired research requirement in PN training by region

general pediatricians was a concern. Similarly, lack of institutional or government support and resources was frequently mentioned by respondents from Africa (60\%), Asia (32\%), Latin America (33 \%), and the Middle East (22 \%) as an obstacle to trainee recruitment. Strengthening regional professional associations and their advocacy efforts should be made a high priority.

\section{Policy development, advocacy activities, and collaboration}

Advocacy at government and ministry levels is also needed to support policy development and resource allocation that are favorable to both established and developing PN communities. We recommend utilizing World Kidney Day as a platform for such advocacy [21]. These interventions must be tailored to the political, social, and institutional environments and will vary by region and country. We also suggest that regional and international PN societies develop resources to assist with this form of advocacy. Interventions to bolster training opportunities and develop long term institution to institution support such as the ISN's Sister Renal Center Program, IPNA's fellowship training grants, and the annual International Pediatric Nephrology Fellows Conference are additional examples of ongoing efforts to support the PN workforce [11, 22-25].

\section{Other activities}

Future assessments of the PN workforce might consider incorporating additional factors such as pediatric population size, rural versus urban disparities, PN training requirements, physician remuneration, and healthcare expenditure. Building a comprehensive and up-to-date database of practicing pediatric nephrologists, physician extenders, nurse practitioners, and dialysis personnel will be of integral to the success of these efforts. Other interventions to support the growth of PN workforce include developing and sharing novel teaching tools, strengthening existing trainee relationships, broadening and facilitating mentorship relationships across institutions, exposing potential trainees to nephrology early in their education, training nurse practitioner and mid-level providers, and engaging potential trainees in national level meetings and conferences. Journal editors and guideline committees should be committed to publish research, guidelines, and conference recommendations that are relevant and practical for PNs working in low resource settings. Initiatives to this effect, for example, include the recent KDIGO Implementation Strategies Conference on Understanding Needs in Low and Middle Income Countries [26].

To our knowledge, this is the first worldwide assessment of the PN workforce. Strengths of our study include its quantitative and qualitative assessments of the PN workforce and broad international reach. Furthermore, the geographic distribution of respondents closely mirrored that of non-respondents (see Table 1). Our results must be considered in the context of study limitations. Our response rate of $15 \%$ is modest; however, this response rate is consistent with previous multinational web-based surveys of physicians [27-32]. Second, the survey did not differentiate between active $(\sim 1300)$ and inactive IPNA members, rendering it subject to participation by PNs no longer in active practice. Third, the survey was an English language, internet-based survey, resulting in possible under-coverage and response bias. The survey should be translated into other languages for future, broader evaluations of the PN global workforce. Fourth, selection bias, especially regarding free-text responses, is potentially 
operative in our data. We speculate the direction of bias to be towards greater workforce inadequacy. Finally, we recognize the high degree of variation likely to be found both across geographic regions and within individual countries. Future surveys should aim for higher response rates to allow for additional sub-regional analyses.

\section{Conclusions}

These data provide a broad assessment of perceptions of the global PN workforce, and have potential implications for workforce planning, policy development, and advocacy campaigns. Efforts could include capitalizing on the elegance of our organ system by developing innovative and inspiring teaching tools, re-imagining ways of sharing responsibility and clinical care coverage to improve work-life balance, joining together to advocate for resources and recognition in developing nations, reigniting discussions regarding training duration and research requirements, and strengthening research and training partnerships across the globe. These goals should be accomplished while combating erosion of our scope of practice by other specialties and maintaining full dedication and service to our patients and their families.

\section{Additional files}

Additional file 1: Survey Response Data. Description of data: Survey response data for perceived workforce adequacy, difficulty recruiting trainees, difficulty finding a job after training, optimal training duration, and mandatory research requirement. (PDF $438 \mathrm{~kb}$ )

Additional file 2: CHERRIES Checklist. Description of data: Checklist for reporting results of Internet Surveys. (PDF 299 kb)

Additional file 3: Global Pediatric nephrology Workforce Questionnaire. Description of data: Survey Instrument. (DOCX $16 \mathrm{~kb}$ )

\section{Abbreviations}

IPNA, International Pediatric Nephrology Association; NZ, New Zealand PN, pediatric nephrology; PNs, pediatric nephrologists

\section{Acknowledgments}

The authors would also like to acknowledge the support of Dr. Jenny Flythe and Dr. Susan Hogan in the preparation of this manuscript.

\section{Funding}

The study was supported in part by a grant from the Renal Research Institute, New York, NY.

\section{Availability of data and materials}

The survey instrument, survey response data, and CHERRIES checklist are available as electronic supplementary material.

\section{Authors' contributions}

DG designed the survey, analyzed the data, and was the primary author of the manuscript. SO, MN, YZ assisted with survey design, deployment, and statistical analysis. These author also contributed to drafting of the manuscript. AW, PC, WP, and MF substantially contributed to project conception, survey design, data interpretation, and manuscript drafting. All authors read and approved the final manuscript.

\section{Competing interests}

The authors declare that they have no competing interests.
Consent for publication

Not applicable.

\section{Ethics approval and consent to participate}

The study was deemed exempt by the Human Research Ethics Committee of the University of North Carolina Chapel Hill (IRB\# 15-1624). Implied consent was obtained prior to survey participation.

\section{Author details}

'UNC Kidney Center, University of North Carolina at Chapel Hill, 7024 Burnett-Womack, Chapel Hill, NC 27599-7155, USA. ${ }^{2}$ Division of Nephrology, Children's Hospital at Dartmouth, 1 Medical Center Drive, Lebanon, NH 03766, USA. ${ }^{3}$ Service de Néphrologie Rhumatologie Dermatologie, Hôpital Femme Mère Enfant \& Université Claude-Bernard, Lyon 1, 69677 Bron Cedex, France.

Received: 11 March 2016 Accepted: 24 June 2016

Published online: 15 July 2016

\section{References}

1. Primack WA, Meyers KE, Kirkwood SJ, et al. The US Pediatric Nephrology Workforce: A Report Commissioned by the American Academy of Pediatrics. Am J Kidney Dis. 2015;66:33-9. doi:10.1053/j.ajkd.2015.03.022.

2. Bourquia A. Issues and challenges of pediatric nephrology in Africa. IPNA Curr. 2016:3:3-7.

3. Reid C. An Overview of Pediatric Nephrology in the UK. IPNA Curr. 2015;2:23.

4. Eddy A. An Overview of Pediatric Nephrology in Canada. IPNA Curr. 2015;2: 2-3.

5. Lozano R, Naghavi M, Foreman K, et al. Global and regional mortality from 235 causes of death for 20 age groups in 1990 and 2010: a systematic analysis for the Global Burden of Disease Study 2010. Lancet. 2010;380: 2095-128. doi:10.1016/S0140-6736(12)61728-0.

6. Thomas B, Wulf S, Bikbov B, et al. Maintenance Dialysis throughout the World in Years 1990 and 2010. J Am Soc Nephrol. 2015;26:2621-33. doi:10. 1681/ASN.2014101017.

7. Luyckx VA, Brenner BM. Birth weight, malnutrition and kidney-associated outcomes[mdash]a global concern. Nat Rev Nephrol. 2015;11:135-49.

8. Allison SJ. The globalization of nephrology. Nat Rev Nephrol. 2015;11:125.

9. The Lancet The global issue of kidney disease. The Lancet. 382:101. doi: 10. 1016/S0140-6736(13)61545-7

10. Phadke K, Bagga A. Training in pediatric nephrology for developing countries. Pediatr Nephrol. 2005;20:1205-7. doi:10.1007/s00467-005-1972-z.

11. Harambat J, Ekulu PM (2015) Inequalities in access to pediatric ESRD care: a global health challenge. Pediatr Nephrol 1-6. doi: 10.1007/s00467-015-32637

12. Stapleton FB, Andreoli S, Ettenger R, et al. Future workforce needs for pediatric nephrology: an analysis of the nephrology workforce and training requirements by the Workforce Committee of the American Society of Pediatric Nephrology. J Am Soc Nephrol. 1997:8:S5

13. Rosenberg DI, Moss MM. Guidelines and levels of care for pediatric intensive care units. Pediatrics. 2004;114:1114-25. doi:10.1542/peds.2004-1599.

14. Program NRM. Results and Data: Specialties Matching Service 2015 Appointment Year. Washington, DC: National Resident Matching Program; 2015.

15. Sharif MU, Elsayed ME, Stack AG. The global nephrology workforce: emerging threats and potential solutions! Clin Kidney J. 2016;9:11-22. doi:10.1093/ckj/sfv111.

16. Field M. Addressing the global shortage of nephrologists. Nat Clin Pr Neph. 2008:4:583. doi:10.1038/ncpneph0951.

17. Salsberg E, Quigley L, Masselink L, et al. The US Nephrology Workforce 2015: Development and Trends. Washington DC: American Society of Nephrology; 2015.

18. Qualtrics. Qualtrics, Provo, Utah, USA

19. Ferris $M$, Iglesia $E$, Ko Z, et al. Wanted: pediatric nephrologists! — why trainees are not choosing pediatric nephrology. Ren Fail. 2014;36:1340-4. doi:10.3109/0886022X.2014.937671.

20. Weinstein AR, Reidy K, Norwood VF, Mahan JD. Factors Influencing Pediatric Nephrology Trainee Entry into the Workforce. Clin J Am Soc Nephrol. 2010; 5:1770-4. 
21. ISN - Global Operations Center World Kidney Day. http://www.worldkidneyday. org/. Accessed 23 Feb 2016

22. International Pediatric Nephrology Assosiation IPNA Online | Fellowship Program. https://www.ipna-online.org/education/fellowship-program/. Accessed 5 Feb 2016

23. International Society of Nephrology Sister Renal Centers Program. http://www.theisn.org/programs/sister-renal-centers-program. Accessed 5 Feb 2016

24. Watson AR, Abdelraheem M, Ali E-TMA, et al. Developing paediatric nephrology in a low-income country using a sister renal centre link: the Sudan experience. Pediatr Nephrol. 2010;25:1569-71. doi:10.1007/s00467009-1421-5.

25. Marra G, Edefonti A, Silva Galan Y, et al. Relevance of a database for monitoring a cooperative paediatric nephrology project in Nicaragua. Pediatr Nephrol. 2010;26:641-2. doi:10.1007/s00467-010-1681-0.

26. Implementation Strategies Conference. In: Kidney Dis. Improv. Glob. Outcomes. http://kdigo.org/home/conferences/implementation-strategies/. Accessed 18 Feb 2016

27. Ghahramani N, Karparvar Z, Ghahramani M, Shadrou S. International survey of nephrologists' perceptions and attitudes about rewards and compensations for kidney donation. Nephrol Dial Transplant. 2013;28:161021. doi:10.1093/ndt/gft079.

28. Ginzburg E, Dujardin F. Physicians' perceptions of the definition of major bleeding in major orthopedic surgery: results of an international survey. J Thromb Thrombolysis. 2010;31:188-95. doi:10.1007/s11239-010-0498-9.

29. Aiyagari V, Pandey DK, Testai FD, et al. A Prototype Worldwide Survey of Diagnostic and Treatment Modalities for Stroke. J Stroke Cerebrovasc Dis. 2015;24:290-6. doi:10.1016/j.jstrokecerebrovasdis.2014.08.002.

30. Dallongeville J, Banegas JR, Tubach F, et al. Survey of physicians' practices in the control of cardiovascular risk factors: the EURIKA study. Eur J Prev Cardiol. 2012;19:541-50. doi:10.1177/1741826711407705.

31. Berns JS. A Survey-Based Evaluation of Self-Perceived Competency after Nephrology Fellowship Training. Clin J Am Soc Nephrol. 2010;5:490-6. doi:10.2215/CJN.08461109.

32. Fluck RJ, Fouque D, Lockridge RS. Nephrologists' perspectives on dialysis treatment: results of an international survey. BMC Nephrol. 2014;15:1-8. doi:10.1186/1471-2369-15-16.

\section{Submit your next manuscript to BioMed Central and we will help you at every step:}

- We accept pre-submission inquiries

- Our selector tool helps you to find the most relevant journal

- We provide round the clock customer support

- Convenient online submission

- Thorough peer review

- Inclusion in PubMed and all major indexing services

- Maximum visibility for your research

Submit your manuscript at www.biomedcentral.com/submit

) Biomed Central 